\title{
Creating patient-centered radiology reports to empower patients undergoing prostate magnetic resonance imaging
}

Nathan Perlis ${ }^{1}$; Antonio Finelli ${ }^{1}$; Mike Lovas²; Alejandro Berlin ${ }^{3}$; Janet Papadakos ${ }^{4}$; Sangeet Ghai $^{5}$; Vasiliki Bakas ${ }^{6}$; Shabbir Alibhai ${ }^{7}$; Odelia Lee ${ }^{2}$; Adam Badzynski ${ }^{2}$; David Wiljer ${ }^{8}$; Alexis Lund $^{1}$; Amelia Di Meo ${ }^{1}$; Joseph Cafazzo ${ }^{9}$; Masoom Haider ${ }^{10}$

${ }^{1}$ Department of Surgery, Division of Urology, University Health Network, Princess Margaret Cancer Centre, University of Toronto, Toronto, ON, Canada; ${ }^{2}$ Healthcare Human Factors, University Health Network, University of Toronto, Toronto, ON, Canada; ${ }^{3}$ Radiation Medicine Program, University Health Network, Princess Margaret Cancer Centre, University of Toronto, Toronto, ON, Canada; ${ }^{4}$ Cancer Health Literacy Research Centre, Princess Margaret Cancer Centre, Patient Education, Cancer Care Ontario; Institute for Health Policy, Management \& Evaluation, University of Toronto, Toronto, ON, Canada; ${ }^{5}$ Joint Department of Medical Imaging, University Health Network, University of Toronto, Toronto, ON, Canada; ${ }^{6}$ Operations, myUHN Portal, University Health Network, University of Toronto, Toronto, ON, Canada; ${ }^{7}$ Division of General Internal Medicine and Geriatrics, University Health Network, University of Toronto, Toronto, ON, Canada; ${ }^{8}$ Education Technology and Innovation, University Health Network, University of Toronto, Toronto, ON, Canada; ${ }^{9}$ Centre for Global eHealth Innovation, University Health Network, Toronto General Hospital, Toronto, ON, Canada; ${ }^{10}$ Joint Department of Medical Imaging, Sinai Health System, University of Toronto, Toronto, ON, Canada

Acknowledgements: The University Health Network (UHN) Research Ethics Board reviewed and approved the study. It is in ethical compliance with ICH-GCP guidelines. Dr. Nathan Perlis, and authors thank the Canadian Urological Association Scholarship Foundation (CUASF) for providing funding for this project. Dr. Perlis reports from Canadian Urological Association Scholarship Foundation (CUASF) - Early Investigator Research Scholarship, during the conduct of the study.

Cite as: Perlis N, Finelli A, Lovas M, et al. Creating patient-centered radiology reports to empower patients undergoing prostate magnetic resonance imaging. Can Urol Assoc J 2020 September 28; Epub ahead of print. http://dx.doi.org/10.5489/cuaj.6585

Published online September 28, 2020

$* * *$

\section{Abstract}

Introduction: As we progress to an era when patient autonomy and shared decision-making are highly valued, there is a need to also have effective patient-centered communication tools. Radiology reports are designed for clinicians and can be very technical and difficult for patients to understand. It is important for patients to understand their magnetic resonance imaging (MRI) report in order to make an informed treatment decision with their physician. Therefore, we aimed 
Patient-centered radiology reports for informed decision-making

to create a patient-centered prostate MRI report in order to give our patients a better understanding of their clinical condition.

Methods: A prototype patient-centered radiology report (PACERR) was created by identifying items to include based on opinions sought from a group of patients undergoing prostate MRI and medical experts. Data was collected in semi-structured interviews using a salient belief question. A prototype PACERR was created in collaboration with human factors engineering and design, medical imaging, biomedical informatics, and cancer patient education groups.

Results: Fifteen patients and eight experts from urology, radiation oncology, radiology, and nursing participated in this study. Patients were particularly interested to have a report with laymen terms, concise language, contextualization of values, definitions of medical terms, and next course of action. Everyone believed the report should include the risk of MRI findings actually being cancer in the subsequent biopsy.

Conclusions: A prostate MRI PACERR has been developed to communicate the most important findings relevant to decision-making in prostate cancer using patient-oriented design principles. The ability of this tool to improve patient knowledge and communication will be explored.

\section{Introduction}

Clinical decisions in urologic oncology often hinge on medical images and the details contained in radiology reports. However, these radiology reports are intended for medical experts, and are notoriously difficult for patients to comprehend [1]. A prostate MRI is primarily used for patients with previous negative prostate biopsies and rising serum PSA, or those on active surveillance [2]. Prostate MRI images are confusing to interpret due to the multiple phases of study, common false positives, complex anatomy and limitations of currently used grading systems [2]. Furthermore, the actual images are not routinely displayed to patients in a clinical setting. In an era where patient autonomy and shared decision making are paramount [3], how can patients be expected to make informed decisions based on information designed for medical experts? Clinicians need a simplified yet thoughtful approach to communicate the imaging test results, their implications, and subsequent therapeutic options to patients.

Targeted interventions to the patient experience have been associated with improved clinical safety and effectiveness [4]. Recognizing this, and in consultation with 6000 patients, Ontario enacted the Patients First Act, 2016, with a primary goal of giving patients and caregivers stronger voices in the health care system [5]. The aim is to improve education, information and transparency so that patients can make informed decisions about their health. As a first step, many hospitals are connecting patients to their medical results through web-based portals. This improves transparency but may actually harm patients if appropriate health literacy or understanding for interpreting the data is lacking [1]. Furthermore, clinicians routinely help 
patients synthesize test results using various communication techniques, but when patients look at the results on their own prior to the clinical encounter, this support system is missed [6].

Several groups are exploring novel ways to enhance communication between clinicians and patients. In urologic oncology, patient-centered pathology reports in bladder cancer have been demonstrated to improve patient knowledge and patient-provider communication [7]. Patient self-efficacy, a measure of patient perception regarding their own performance accomplishment, may also be bolstered by these types of reports [8]. When patients are more confident in their role as decision makers and informed consumers they are likely to be more resilient as the course of their disease unfolds and more satisfied with care.

Unfortunately, while some adjunct glossaries are available to "translate" complex language found in radiology reports, translation may not be able to clarify reports enough for patients to be able to rely on them for decision making because, in addition to language, the picture itself has to be translated [9]. The patient- and expert-guided development of a radiology report designed specifically for patients could transform very important and common clinical encounters by making patients more active participants in their own care. In this study we aimed to develop a prototype patient-centered radiology report (PACERR) for prostate MRI.

\section{Methods}

Given the limited published precedent for creating patient-centered reports, we adapted the approaches from user-centered design processes and psychometric instrument creation methodologies [10]. Overall, the prototype was created in three phases. In phase 1, items to include in the report were identified. The PACERR was designed in phase 2, and the report was pilot tested for validity and usability in phase 3. Institutional ethics approval (ID\# 17-5224.4) was granted for this study. All patients and experts provided informed consent prior to study inclusion.

In phase 1, patients and experts were recruited for one-on-one interviews where their ideas on which items were most important to include in the prostate MRI PACERR were explored. From previous groups' work creating patient-centered pathology reports, we expected saturation of items to occur at approximately 15-25 patients and 8 experts [7]. Two experts from each of urology, radiation oncology, radiology and nursing were interviewed using a script (Appendix 1). During the accrual period, all men undergoing clinical prostate MRI for any indication were screened and approached for study inclusion. Patients were interviewed face-toprior to their MRI using a semi-structured interview guide (Appendix 2). Once the prototype was developed, the same group of patients were then offered participation in usability testing for the prototype PACERR.

Interviews were based on a salient belief question which is a simple method of eliciting people's viewpoints with minimal burden [10]. Patients were provided with a paper with ten blank lines and asked to fill in the spaces relating to the following sentence: "When you think of your prostate MRI radiology report, what do you think about". Following the interview, patients 
were given a sample MRI report sheet to help familiarize themselves with the structure of a typical MRI report. The interviewer clarified each item. Patients were asked to rate the relative importance of each piece of information on a Likert scale from 1 to 5 ( 5 being most important). If the interviewer noticed that particular concepts were overlooked by patients, they used the interview script to prompt any further items.

Phase 2 was then carried out. In collaboration with medical imaging, biomedical informatics, human factors engineering and the health literacy research center, and using the item importance scores as a guide, the research team generated design principles and then two prototype reports (a less detailed and more detailed version) with a simple attached glossary.

In phase 3 the prototype PACERR was pilot tested using cognitive interviewing and iterative design feedback to evaluate and refine the design and content and to decide which version would be the final one [11] (Appendix 3). Using these techniques, confusing or ambiguous sections were rectified. Patients were also solicited regarding PACERR relevance to their health knowledge and ability to participate in a productive shared decision making process. Results of the pilot test were collated by theme and organized into topics, insights and design recommendations and the final prototype was finalized.

\section{Results}

Phase 1 was carried out between June and December 2018, 18 patients were approached, of which 15 provided consent to participate and were included in the present study. Eight experts from surgery (2), radiation oncology (2), radiology (2) and nursing (2) also participated. Patient characteristics including disease state are shown in Table 1. Items from the salient belief questionnaire and interview \#1 were thematically synthesized and ranked. Likert scoring for item significance did not significantly change the ranking as the mean significance scores for all items were similar. Thus, we were guided primarily by the number of patients and experts endorsing each item (Figure 1).

In phase 2 themes from patient interviews were used to develop three main design principles for the PACERR: (a) The PACERR meets the patients at their level of understanding. The tone of voice and assistive visuals are approachable and relatable to patients, (b) The PACERR informs without being overwhelming; each component is clear, concise and guiding. Patients are led to understand their results and are equipped with knowledge to identify and navigate the steps ahead. (c) The product enables a space for conversation. Clean and directed information facilitates a meaningful interaction between patient and caregiver. Both long and short PACERR prototypes were generated (Appendix 4). The main difference between the two versions was the inclusion of the PI-RADS score in the long version.

For phase 3, the pilot testing sessions were carried out over 5 weeks with 11 patients in 8 sessions. We reviewed both the long and short PACERR versions (A/B testing) in alternating sequence for sequential sessions focusing on situational questions for three main PACERR sections: Patient information and MRI information, Prostate MRI Results, and What's Next. 
Feedback on the glossary was also collected. User testing summary is contained in Table 2 . The most frequent patient suggestion was to keep the language in laymen's terms and the product concise. Therefore, only the most paramount findings are presented in the PACERR. For example, after A/B product testing, the PI-RADS score was abandoned despite its importance in the traditional radiology report for healthcare providers. Instead, we adapted the underlying concepts of the PI-RADS scoring system and created a plain language method to communicate a likelihood of harboring underlying malignancy. In this sense, a lesion with a particular PI-RADS score became a "spot" with a high or low "chance" of containing cancer.

Based on patient input we elected to have a picture of a man standing and focus into the pelvis in a sagittal view. Although this does not give as much detail as offering two simultaneous views (i.e. axial and sagittal), patients preferred a single view, and seemed to comprehend the sagittal view the best. This orientation also facilitated the depiction of the adjacent organs and pelvic floor, which are relevant for explaining possible treatment-related complications, a concept deemed important by experts and patient. Final prototype PACERR and glossary are shown in Figures 2 and 3.

\section{Discussion}

In this study, a prototype patient-centered radiology report (PACERR) for prostate MRI was created. To ensure that the report would be relevant to patients and practical to use, we included patients throughout the project phases and were guided by a framework created by experts in healthcare design and patient literacy. Using an iterative process, we first collected general concepts from patients and experts regarding most important contents for the PACERR. We then constructed a viable prototype that was continuously refined until a satisfactory final version was reached.

Findings contained within traditional radiology reports often drive patients' decisions and are relied upon when informed consent is sought for interventions. To make the consent process patient-centered, some argue that the materials presented to patients need to be targeted to them and framed around their own objectives [10]. Accordingly, our work is based on the premise that there is no better way to lead a patient to an informed decision than by offering knowledge framed in patient-oriented language and design. However, conveying information contained in radiology reports in a patient-centered manner is particularly challenging as both the language and image need to be adequately explained.

In the past, radiology reports have been a private means of communication between radiologists and other physicians [14]. However, with the rise of patient portals, patients have access to their radiology reports in real time [15]. Radiology reports specifically have been determined to be one of the most difficult sections of the health record to comprehend [12]. It has been discovered that the information described by patients as "most needed" was often inaccessible to them due to the difficult concepts, abbreviations, and medical terminology [12]. Even highly educated individuals found reading their radiology report to be quite difficult [12]. 
The prostate MRI PACERR is designed to be used alongside the traditional report and in conjunction with the attached glossary. PACERR prioritizes simplicity, clarity and simple language targeted at a sixth grade level so that men and their families from varying education and language backgrounds can comprehend its content. It is important to balance the imperative to be transparent with patients without inciting unnecessary fear and anxiety. For that reason, we added the section on "next steps", highlighting that the results whether positive or negative, need to be discussed with a healthcare provider, and offering contact information to make sure a follow-up appointment is organized at an appropriate time.

The physical layout of the report was carefully designed. Line drawings are simple but able to transmit context of important adjacent structures to the prostate that are relevant to consider when making subsequent biopsy and/or treatment decisions. Furthermore, line drawings offer useable blank space so that clinicians and patients can sketch notes or details on the same image to help patients comprehend clinically-important concepts. Due to the complexity of pelvic anatomy, decisions pertaining prostate sketching were challenging.

In an age of patient access to their medical records in real-time, it was also important to balance the imperative to be transparent with patients without inciting unnecessary fear and anxiety. For that reason, we added the section on "next steps", highlighting that the results, whether positive or negative, need to be discussed with a healthcare provider, and offering contact information to make sure a follow-up appointment is organized at an appropriate time.

The PACERR project has several strengths. Although there is minimal published literature on designing patient-centered reports, we used the salient belief question and design usability testing, which are well-validated approaches for identifying key pieces of information from patients and refining new instruments. Additionally, we were guided primarily by patient input and had a study team with wide spectrum of expertise. Finally, despite interviewing a relatively small number of patients and experts for this project, saturation was met, and we did not feel that any additional patients were needed to refine the product.

There are several limitations to our study. First, because patients with inadequate health literacy are more likely to elect not to participate in research studies [13], our patient sample is likely inflated with men with higher health literacy. High order health literacy skills including reading consent forms, completing measures and surveys, as well understanding the purpose of the research and what participation entails are required to participate in these activities. Second, the prostate PACERR is context specific. We tried to include men from various clinical situations, however we did not have a lot of men who were biopsy naïve, which is a growing category of men undergoing prostate MRI.

\section{Conclusions}

We present the creation of a novel patient-centered prostate MRI prototype report. The overarching goal was to better inform patients, without overburdening them with medical terminology, hence allowing better preparation and sufficient space for directed conversation at 
the time of encounter with their healthcare provider. This study serves as the backbone of what we hope will emerge as a useful complement to traditional radiology reports for patients and we believe the methods presented can be used to generate reports for other disease sites and modalities. The ability of this tool to improve patient knowledge and communication is being explored in a clinical trial. 


\section{References}

1. Hall FM (2009) The Radiology Report of the Future 1. Radiology 251(2):313-6.

2. Turkbey B, Choyke PL (2012) Multiparametric MRI and prostate cancer diagnosis and risk stratification. Curr Opin Urol 22(4):310-5.

3. Barry MJ, Edgman-Levitan S (2012) Shared decision making - the pinnacle of patientcentered care. New Engl J Med 366(9):780-1.

4. Doyle C, Lennox L, Bell D (2013) A systematic review of evidence on the links between patient experience and clinical safety and effectiveness. BMJ Open 3(1):e001570.

5. Government of Ontario. Patients first: A Proposal to strengthen patient-centered health care in Ontario. Toronto, Canada: Queen's Printer for Ontario; 2015.

6. Schwartzberg JG, Cowett A, VanGeest J, et al. (2007) Communication techniques for patients with low health literacy: A survey of physicians, nurses, and pharmacists. Am $J$ Health Behav 31:S96

7. Mossanen M, Macleod LC, Chu A, et al. (2016) Comparative effectiveness of a patient centered pathology report for bladder cancer care. J Urology 196(5):1383-9.

8. Schwarzer R (2014) Self-efficacy: Thought control of action, $1^{\text {st }}$ edn. Taylor $\&$ Francis New York

9. Oh SC, Cook TS, Kahn CE (2016) PORTER: A prototype system for patient-oriented radiology reporting. J Digit Imaging 29(4):450-4.

10. Papadakos CT, Papadakos J, Catton P, et al. (2014) From theory to pamphlet: the $3 \mathrm{Ws}$ and an $\mathrm{H}$ process for the development of meaningful patient education resources. Journal of Cancer Education 29(2):304-10.

11. Gulliksen J, Göransson B, Boivie I, et al. (2003) Key principles for user-centered systems design. Behavior and information technology 22(6):397-409.

12. Keselman A, Slaughter L, Arnott-Smith C, et al. (2007) Towards consumer-friendly PHRs: patients' experience with reviewing their health records. American Medical Informatics Association (AMIA) Annual Symposium Proceedings 2007. (399-403).

13. Kripalani S, Heerman WJ, Patel NJ, et al. (2019) Association of health literacy and numeracy with interest in research participation. Journal of General Internal Medicine 34(4):544-51.

14. Bruno MA, Petscavage-Thomas JM, Mohr MJ, et al. (2014) The "open letter": radiologists' reports in the era of patient web portals. J Am Coll Radiol. 11(9):863-867.

15. Corey W Arnold, Mary McNamara, Suzie El-Saden et al. (2013) Imaging informatics for consumer health: towards a radiology patient portal, Journal of the American Medical Informatics Association 20(6): 1028-1036 


\section{Figures and Tables}

Fig. 1. Items endorsed by a group of patients undergoing prostate magnetic resonance imaging (MRI) and prostate cancer experts as important to include in a patient-centered prostate MRI report via semi-structured interviews and collated using thematic analysis.

ITEMS IDENTIFIED BY PATIENTS TO INCLUDE

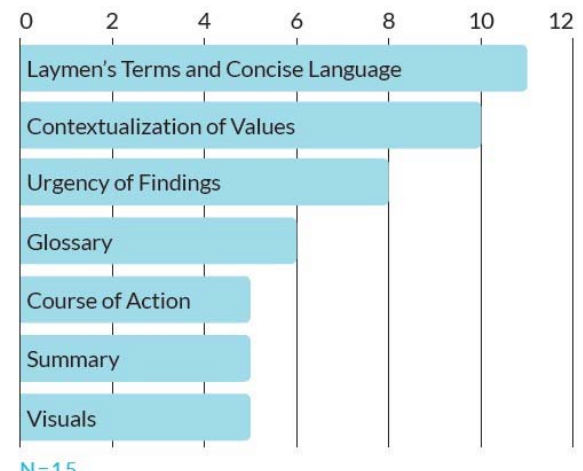

ITEMS IDENTIFIED BY EXPERTS TO INCLUDE

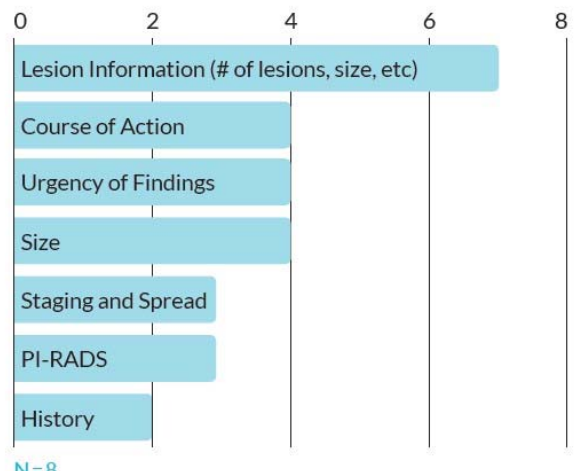


Fig. 2. Final prostate magnetic resonance imaging prototype patient-centered radiology report (MRI PACERR).

\section{MRI REPORT - PROSTATE sUMMARY FOR PATIENTS}

- patient information

NAME Doe

DATE OF BIRTH ID

Sep 29, 1948
MRI INFORMATION

ORDERING PHYSICIAN

Dr. Jane Doe

DATE OF MRI REASON FOR MRI

May 9, 2019 Active Surveillance for low-risk prostate cancer

\section{YOUR PROSTATE MRI RESULTS}

Your MRI scan shows that you have a low chance of cancer in your prostate. We found one spot of interest which is detailed below. Additionally, you have a very enlarged prostate. For further explanation of your findings, please refer to attached glossary.

SPOTS ON YOUR MRI SCAN

\begin{tabular}{|l|ll|}
\hline Spot $\quad$ Chance of Cancer (based on appearance) & Size of Spot & Side of Prostate \\
\hline (4) Low Chance & Small $(8 \mathrm{~mm})$ & Right \\
\hline & \\
\hline
\end{tabular}

YOUR MRI SCAN

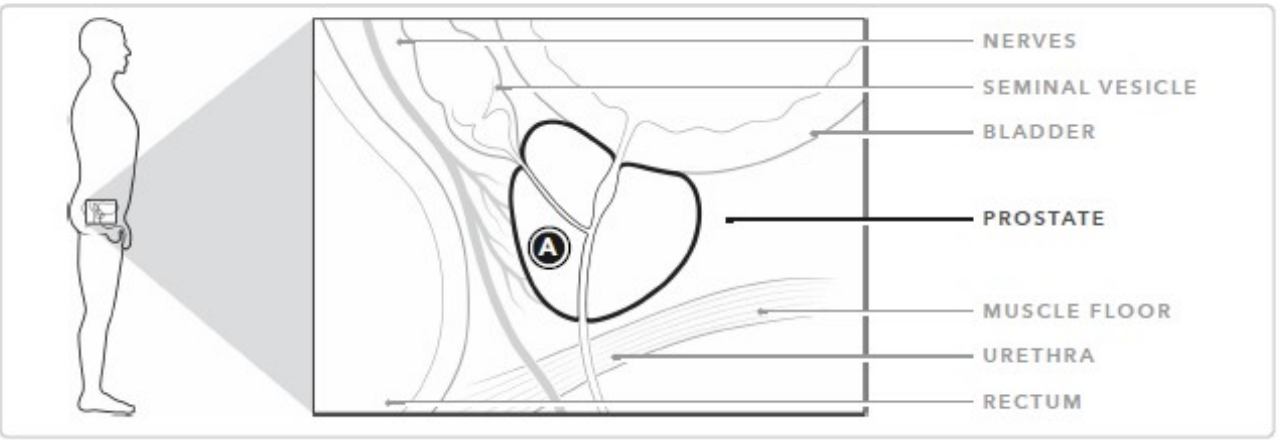

YOUR ADDITIONAL FINDINGS

Very Enlarged Prostate

\section{WHAT'S THE NEXT STEP?}

All results should be reviewed with your ordering physician, please contact the office if you do not have an upcoming appointment booked.

\section{OFFICE CONTACT}

Urology Clinic gu.nurses@hospital.com 1-800-123-1234 
Fig. 3. Patient-centered glossary for prostate magnetic resonance imaging prototype patientcentered radiology report (MRI PACERR).

\section{GLOSSARY FOR MRI REPORT}

This glossary is meant to explain words found in the prostate MRI report above. If you still have

additional questions, please speak with your doctor.

\section{GENERAL MRI INFORMATION}

MRI - This stands for "Magnetic Resonance Image." An MRI is an imaging test that uses magnets and radio waves to create images.

Spot(s) of Interest - Areas on an MRI that look different from normal tissue.

Chance of Cancer - To determine whether a spot of interest contains cancer, a biopsy must be done.

\section{】 ANATOMY AROUND THE PROSTATE}

Nerves - Tissues that carry electrical signals throughout the body.

Seminal Vesicles - Glands that add nutrients to semen (the fluid released from the penis that contains sperm). Seminal vesicles are connected to the prostate. They are located just below the bladder.

Bladder - A balloon-shaped organ that holds pee.

Prostate - This gland produces liquid that mixes with sperm from the testicles to make semen. It is located under the bladder and in front of the rectum. Part of the urethra runs through it.

Muscle Floor - The muscles below the prostate, on the pelvic floor. When these muscles are damaged or weak, pee can leak.

Urethra - A tube that carries pee from the bladder out of the body through the penis.

Rectum - The last section of the intestines. The rectum is behind the prostate.

\section{ADDITIONAL FINDINGS}

Benign - This type of tissue is not cancer and not dangerous. It will not spread to other areas of the body.

BPH - This stands for "Benign Prostatic Hyperplasia," an enlarged prostate. This is common in older men. An enlarged prostate due to BPH compresses the urethra and makes it difficult to pee.

Prostatitis - Inflammation (the body's protective response to an infection) of the prostate gland. Prostatitis may be caused by an infection. Men of all ages can be affected. When men have prostatitis they can have painful prostates and can experience irritation when they pee.

Lymphadenopathy - Abnormal growth of the lymph nodes. This may be due to cancer or due to benign inflammation.

Metastasis - When cancer cells from one part of the body (e.g. prostate) spread to another part of the body. 


\begin{tabular}{|c|c|}
\hline \multicolumn{2}{|l|}{ Age $(n=15)$} \\
\hline Median, years & 67 \\
\hline IQR & $58-75$ \\
\hline \multicolumn{2}{|l|}{ Occupational status $^{*}(\mathrm{n}=11)$} \\
\hline Retired & 4 \\
\hline Employed & 6 \\
\hline Unemployed & 1 \\
\hline \multicolumn{2}{|l|}{ Disease state $(n=15)$} \\
\hline Active surveillance & 7 \\
\hline Focal treatment & 5 \\
\hline Elevated PSA, prior negative biopsy & 2 \\
\hline Elevated PSA, biopsy-naive & 1 \\
\hline
\end{tabular}

*Based on those who also participated in pilot testing. IQR: interquartile range; PACERR: prototype patient-centered radiology report; PSA: prostate-specific antigen. 


\begin{tabular}{|c|c|c|c|}
\hline $\begin{array}{l}\text { Component of } \\
\text { PACERR }\end{array}$ & Observations & Recommendations & Patient quotes \\
\hline $\begin{array}{l}\text { Patient and MRI } \\
\text { Information }\end{array}$ & $\begin{array}{l}\text { - Patient may have } \\
\text { multiple medical } \\
\text { numbers across } \\
\text { hospitals } \\
\text { - Patient may have } \\
\text { different physicians } \\
\text { from different } \\
\text { hospitals } \\
\text { - Layout of patient and } \\
\text { MRI information } \\
\text { was clear }\end{array}$ & $\begin{array}{l}\text { - Clearly identify the } \\
\text { origin of the medical } \\
\text { number } \\
\text { - Clearly identify the } \\
\text { origin of ordering } \\
\text { physician }\end{array}$ & $\begin{array}{l}\text { "And surprisingly these } \\
\text { [reports] are not } \\
\text { necessarily } \\
\text { all with Hospital X, so } \\
\text { because I'm at Hospital } \\
\text { Y and I've been to } \\
\text { Hospital Z for certain } \\
\text { tests, this number, so } \\
\text { patient ID needs } \\
\text { references sometimes." }\end{array}$ \\
\hline $\begin{array}{l}\text { Prostate MRI } \\
\text { results - } \\
\text { Overview }\end{array}$ & $\begin{array}{l}\text { - Patients were unclear } \\
\text { that the image and } \\
\text { findings were specific } \\
\text { to their own MRI scan } \\
\text { - Main focus for patients } \\
\text { was the results table, } \\
\text { saw value in the } \\
\text { diagram for later } \\
\text { discussion with } \\
\text { clinician } \\
\text { - Confusion around term } \\
\text { spot because it relates } \\
\text { to their biopsy } \\
\text { procedure }\end{array}$ & $\begin{array}{l}\text { - Build context around } \\
\text { what will be shown in } \\
\text { the results } \\
\text { section } \\
\text { - Add a statement } \\
\text { indicating the } \\
\text { findings/diagram below } \\
\text { are the patient's result, } \\
\text { include total number of } \\
\text { spots that were found, } \\
\text { severity of disease } \\
\text { condition }\end{array}$ & $\begin{array}{l}\text { "So it's not clear. It } \\
\text { doesn't say, 'Mr Smith, } \\
\text { this was you.' It just has } \\
\text { highlighted A, B, C, D. } \\
\text { Am I correct in } \\
\text { assuming that A and B } \\
\text { were his results?" }\end{array}$ \\
\hline $\begin{array}{l}\text { Prostate MRI } \\
\text { results - Table }\end{array}$ & $\begin{array}{l}\text { - Patients main concern } \\
\text { was whether the spots } \\
\text { were cancer/not cancer } \\
\text { - Location of spot was } \\
\text { not relevant to } \\
\text { patients. Side of body } \\
\text { not clearly connected } \\
\text { with side prostate. } \\
\text { - Size and change in size } \\
\text { were poorly } \\
\text { understood }\end{array}$ & $\begin{array}{l}\text { - Evaluate which details } \\
\text { should be presented } \\
\text { beforehand vs. } \\
\text { discussed in clinic. } \\
\text { What details do } \\
\text { clinicians use in clinic } \\
\text { to better communicate/ } \\
\text { connect with their } \\
\text { patients? }\end{array}$ & $\begin{array}{l}\text { "Most people would } \\
\text { think of the prostate as } \\
\text { one spot in the bod and } \\
\text { it's either got cancer or } \\
\text { it don't got cancer. } \\
\text { They would not be } \\
\text { thinking, 'You are } \\
\text { looking at a spot on my } \\
\text { prostate that was } 10 \\
\text { mm in size and now its } \\
15 \text { mm in size.' They're } \\
\text { not, they're not going to } \\
\text { think of that." }\end{array}$ \\
\hline
\end{tabular}




\begin{tabular}{|c|c|c|c|}
\hline $\begin{array}{l}\text { Prostate MRI } \\
\text { results - Chance } \\
\text { of cancer }\end{array}$ & $\begin{array}{l}\text { - The term "possibly" } \\
\text { cancer was confusing } \\
\text { to patients; unsure } \\
\text { whether to interpret } \\
\text { this as bad or good } \\
\text { news } \\
\text { - Patients have a hard } \\
\text { time understanding } \\
\text { degree of cancer. To } \\
\text { them they either have } \\
\text { cancer or don't } \\
\text { - Depending on severity, } \\
\text { patients want to know } \\
\text { whether they need to } \\
\text { act immediately vs. } \\
\text { wait for next } \\
\text { appointment }\end{array}$ & $\begin{array}{l}\text { - It is important to } \\
\text { convey the } \\
\text { implications of the } \\
\text { MRI findings. Revisit } \\
\text { the language and } \\
\text { presentation to clearly } \\
\text { communicate the } \\
\text { severity of their health. } \\
\text { - High chance of cancer, } \\
\text { low chance of cancer }\end{array}$ & $\begin{array}{l}\text { "Well, you know } \\
\text { everything is possibly } \\
\text { cancer. You } \\
\text { know, like, so what?" }\end{array}$ \\
\hline $\begin{array}{l}\text { Prostate MRI } \\
\text { results - PI- } \\
\text { RADS }\end{array}$ & $\begin{array}{l}\text { - PI-RADS terminology } \\
\text { was not familiar to } \\
10 \text { out of } 11 \text { patients } \\
\text { - Patients did not } \\
\text { understand the } \\
\text { meaning of the PI- } \\
\text { RADS scale }\end{array}$ & $\begin{array}{l}\text { Terminology used in } \\
\text { report should be easily } \\
\text { understood } \\
\text { by patient. Information } \\
\text { that requires additional } \\
\text { explanation should be } \\
\text { excluded and placed in a } \\
\text { reference section. }\end{array}$ & $\begin{array}{l}\text { "I found, first of all, I } \\
\text { don't know what a PI- } \\
\text { RADS is. That's your } \\
\text { terminology, but it's not } \\
\text { terminology that is } \\
\text { outside of the medical } \\
\text { profession." }\end{array}$ \\
\hline What's next? & $\begin{array}{l}\text { - Patients look for } \\
\text { definitive next } \\
\text { steps/ treatment } \\
\text { options } \\
\text { - Some patients find this } \\
\text { section helpful, but are } \\
\text { unsure if all results } \\
\text { mandate a followup } \\
\text { appointment } \\
\text { - Patients want to know } \\
\text { the urgency of the } \\
\text { findings (i.e., "Do I } \\
\text { need to go see my } \\
\text { doctor right away?") }\end{array}$ & $\begin{array}{l}\text { - Address what the } \\
\text { patient can do now/ } \\
\text { before their next } \\
\text { appointment } \\
\text { - Personalization of next } \\
\text { steps? }\end{array}$ & $\begin{array}{l}\text { "If the report is about } \\
\text { the same, and there's } \\
\text { nothing happening, and } \\
\text { there's no call for } \\
\text { immediate response or } \\
\text { treatment, that's } \\
\text { probably the more } \\
\text { complex thing. How do } \\
\text { you communicate that } \\
\text { to the patient, that there } \\
\text { isn't anything } \\
\text { immediately required?" }\end{array}$ \\
\hline Glossary & $\begin{array}{l}\text { - Question titles are not } \\
\text { answered in the } \\
\text { terms listed below. } \\
\text { - Additional finding } \\
\text { terms not consistent }\end{array}$ & $\begin{array}{l}\text { Redesign to match report. } \\
\text { Keep concise. }\end{array}$ & N/A \\
\hline
\end{tabular}




\begin{tabular}{|l|l|l|l|}
\hline & $\begin{array}{l}\text { between report and } \\
\text { glossary } \\
\text { - Glossary is a welcome } \\
\text { supplement to the } \\
\text { report; patients would } \\
\text { like reliable references } \\
\text { so that they don't go } \\
\text { finding wrong }\end{array}$ & & \\
information on their & & & \\
own & & \\
\hline
\end{tabular}

